\title{
Effects of codeine on pregnancy outcome: results from a large population-based cohort study
}

\author{
Kateřina Nezvalová-Henriksen • Olav Spigset • \\ Hedvig Nordeng
}

Received: 24 January 2011 / Accepted: 23 May 2011 /Published online: 9 June 2011

(C) The Author(s) 2011. This article is published with open access at Springerlink.com

\begin{abstract}
Background Guidelines on codeine safety during pregnancy rely on small studies with inconsistent results, and associations between codeine use during pregnancy and increased risk of congenital malformations remain unsubstantiated.

Objectives Our objective was to analyze the effect of codeine on pregnancy outcome.

Methods Pregnancy outcomes of 2,666 women who used codeine during pregnancy were compared with 65,316 women who used no opioids during pregnancy. Information on maternal sociodemographic and medical characteristics, potential confounders, and pregnancy outcome was obtained from The Norwegian Mother and Child Cohort Study [den norske Mor \& barn-undersøkelsen (MoBa)] data
\end{abstract}

Electronic supplementary material The online version of this article (doi:10.1007/s00228-011-1069-5) contains supplementary material, which is available to authorized users.

\footnotetext{
K. Nezvalová-Henriksen $(\bowtie) \cdot H$. Nordeng

Department of Social Pharmacy, School of Pharmacy,

Faculty of Mathematics and Natural Sciences, University of Oslo,

Sem Sælands vei 3,

0316 Oslo, Norway

e-mail: katerina.nezvalova-henriksen@farmasi.uio.no

O. Spigset

Department of Clinical Pharmacology,

St Olav's University Hospital,

7006 Trondheim, Norway

O. Spigset

Department of Laboratory Medicine, Children's and Women's

Health, Norwegian University of Science and Technology,

7491 Trondheim, Norway

H. Nordeng

Division for Mental Health, National Institute of Health,

Marcus Thranes gate 6,

0473 Oslo, Norway
}

set and the Medical Birth Registry of Norway (MBRN) data set. The data sets were linked via the maternal personal identification number. Associations between codeine therapy and pregnancy outcomes were identified using logistic regression analyses.

Results No significant differences were found in the survival rate [adjusted odds ratio (OR) $0.9,95 \%$ confidence interval (CI) $0.6-1.5]$ or the congenital malformation rate (adjusted OR 0.9, 95\% CI 0.8-1.1) between codeineexposed and unexposed infants. Codeine use anytime during pregnancy was associated with planned Cesarean delivery (adjusted OR 1.4, 95\% CI 1.2-1.7; $P<0.0001$ ). Third-trimester use was associated with acute Cesarean delivery (adjusted OR 1.5, 95\% CI 1.3-1.8; $P<0.0001$ ) and postpartum hemorrhage (adjusted OR 1.3, 95\% CI 1.1-1.5; $P<0.0001)$. No significant associations with other adverse pregnancy outcomes were found.

Conclusions No effects of maternal codeine intake during pregnancy were observed on infant survival or congenital malformation rate. Our findings are reassuring; however, the association with acute Cesarean delivery and postpartum hemorrhage may justify a certain level of caution when administering codeine toward the end of pregnancy.

Keywords Codeine $\cdot$ Delivery complications $\cdot$ Pregnancy outcome

\section{Introduction}

Few studies address the safety of codeine use during pregnancy despite its extensive use as an analgesic and antitussive in the general population. The frequency of codeine use during pregnancy has been shown to range between $1 \%$ and $3.5 \%$ [1-3]. Studies specifically targeting 
codeine safety during pregnancy are either small casecontrol studies or case reports with inherent methodological limitations that generally warrant cautious interpretation. No data from cohort studies are available to date. One casecontrol study of 504 children with neuroblastoma found an association with in utero exposure to codeine [odds ratio (OR) 3.4, 95\% confidence interval (CI) 1.4-8.4] [4]. Another of 599 infants found that mothers who gave birth to infants with cleft palate or cleft lip with or without cleft palate used opioid analgesics (mainly codeine) much more frequently than the control group; the largest difference was seen for codeine use during the first trimester $(8.6 \%$ compared with $2.1 \%$ of infants in the control group; $P<$ 0.01 ) [5]. In a third case-control study of 1,370 infants, 12 infants with major congenital malformations had been exposed to codeine during the first trimester compared with seven in the control group (OR 3.7, Fisher's one-tailed $P$ value 0.004) [6]. Neonatal abstinence syndrome has been described in two cases in which codeine was used by the mother over a period of several days close to term [7]. Two other reports described an association between neonatal abstinence syndrome and possibly cerebral infarction after maternal intake of codeine close to term [8].

Evidently, most of studies and case reports focus either on the possible teratogenicity of codeine or neonatal abstinence syndrome. The latter has mainly been shown to be associated with other opioids [9]. Other pregnancy outcomes, including postpartum complications, have only been studied in populations using opioid analgesics in general and those of addicted pregnant women [10-12] and not in pregnant women taking codeine in therapeutic doses. It is likely that these studies were subject to bias due to inclusion of populations with very specific sociodemographic and lifestyle characteristics, and the effects of codeine use as such would thus be difficult to evaluate [1012]. Notwithstanding, leading literature sources on the safety of drug use during pregnancy suggest that sporadic use of codeine is safe except toward the end of pregnancy $[9,13]$.

Using data from a large prospective cohort study, our aim was to evaluate the potential teratogenicity of codeine and investigate possible associations with other adverse pregnancy outcomes that have not been studied so far.

\section{Methods}

Data for this study were retrieved from The Norwegian Mother and Child Cohort Study [den norske Mor \& barnundersøkelsen $(\mathrm{MoBa})]$ data set (version four) released in December 2008 and from records from the Medical Birth Registry of Norway(MBRN). MoBa [14] is a prospective cohort study conducted by the Norwegian Institute of
Public Health. The overall aim of the study is to examine the effect of a vast number of exposures on pregnancy outcome and maternal and fetal health during pregnancy and postpartum. Data were obtained from three selfadministered questionnaires answered by pregnant women who participated in the study between 1999 and 2006. Pregnant women received a postal invitation with an informed consent form and the first questionnaire prior to their first ultrasound scan during gestational weeks 17 or 18. This first questionnaire covered the time period between the 6 months prior to pregnancy and the 18th gestational week. The second questionnaire covered the time period between the 19th and 29th gestational week, and the third questionnaire covered the time period from the 30th gestational week until birth. The questionnaires covered sociodemographic and lifestyle data, maternal medical history, maternal health during the pregnancy, drug use, and neonatal health. The overall response rate was $43.5 \%$ [15]. The MBRN [16] encompasses all births in Norway and has been prospectively collecting data on all deliveries since 1967. Approximately 60,000 infants are born in Norway every year, corresponding to an annual birth rate of 1.2 infants per 100 inhabitants. Data stem from mandatory standardized forms filled out by midwives, obstetricians, and/or pediatricians at each delivery and from the mother's pregnancy medical records. The standardized forms cover sociodemographic and lifestyle information on the mother and medical information including maternal health prior to and during pregnancy as well as delivery and postpartum complications and interventions. Data from the two sources were linked via the woman' personal identification number, which is assigned to every legal resident in Norway. The study was approved by the Regional Committee for Ethics in Medical Research, Region South, and the Norwegian Data Inspectorate.

\section{Study population}

The original quality-assured data file released for research in 2008 (version 4) consisted of data on 72,934 women. All these women had a pregnancy outcome registered in the MBRN. Prior to release of this data file, $3.5 \%$ of the women in the study did not have a pregnancy outcome registered, mainly due to spontaneous abortions that happened early on in pregnancy. Of the 72,934 women, 3,005 who did not complete the first questionnaire were excluded. A total of 69,929 pregnant women with records both in both data sets were eligible for inclusion $(95.9 \%$ of the original data file). In addition, women using opioids other than codeine (i.e., ethylmorphine, morphine, ketobemidone, tramadol, pethidine, dextropropoxyphene, oxycodone, buprenorphine, and methadone) $(n=1,664)$ and women using both codeine and one or several of the 
aforementioned opioids $(n=283)$ were excluded. The final study population therefore consisted of 67,982 women (93.2\% of the original data file). Multiple pregnancies were included; however, only data on the first-born infant were used, as only these were linked to maternal data.

\section{Explanatory variables}

Explanatory variables consisted of the following subsets: (i) pregnant women who used codeine (alone or in a fixed combination with paracetamol) during pregnancy (total) (yes/no); (ii) pregnant women who used codeine (alone or in a fixed combination with paracetamol) during the first trimester (gestational weeks 0-12) (yes/no); (iii) pregnant women who used codeine (alone or in a fixed combination with paracetamol) during the second trimester (gestational weeks 13-28) (yes/no); (iv) pregnant women who used codeine (alone or in a fixed combination with paracetamol) during the third trimester (gestational week 29 until delivery) (yes/no). Drug therapy was classified and grouped according to the Anatomical Therapeutic Chemical (ATC) classification system developed by the World Health Organization (WHO) [17]. ATC codes used were R05DA04 (codeine alone) and N02AA59 (codeine in a fixed combination with paracetamol). Codeine in fixed combinations with acetylsalicylic acid or other nonsteroidal antiinflammatory drugs is not available in Norway. The explanatory variable subsets were created using answers to questions regarding both codeine use and maternal illness in questionnaires one and two as long as the ATC code for codeine and the timing of either codeine use or the medical condition was specified. Subanalyses were performed to investigate possible associations between the extent of codeine use (number of days used, categorized as 1-7 days, 8-14 days, and $>14$ days) and pregnancy outcome.

\section{Confounding factors}

Confounding factors included sociodemographic, lifestyle, and medical characteristics (Tables 1 and 2), concomitant drug use (Table 3) (this information was derived from theMoBa questionnaires), and factors related to delivery (this information was derived from the MBRN). Different potential confounding factors, the majority of which are listed in Tables 1-4 were selected for each pregnancy outcome. (Please find the complete list of confounding factors used in the analyses in Electronic supplementary material (ESM) 1: Confounding factors.)

Outcome variables

Outcome variables were retrieved from both $\mathrm{MoBa}$ and MBRN. The choice of outcome variables was based on current information on codeine safety during pregnancy and studies on the effect of opioid analgesics on pregnancy outcome and labor progress, with special focus on prolonged labor and neonatal complications. The chosen variables consisted of any congenital malformations detected at birth, major congenital malformations detected at birth, survival (live birth, miscarriage/stillbirth, perinatal death, death during the first 12 months of life), birth weight $<2,500$ g, gestational age $<37$ weeks, Apgar scores $<7$ at 1 and $5 \mathrm{~min}$, neonatal respiratory depression, neonatal hypoglycemia, newborn admitted to intensive care unit, acute Cesarean delivery, planned Cesarean delivery, atonic uterus, prolonged labor, and postpartum hemorrhage $>500 \mathrm{ml}$. All outcome variables were dichotomized into yes or no categories.

\section{Statistical analysis}

Logistic regression analyses were performed to identify significant associations between codeine therapy and pregnancy outcome. Subsets of confounding factors were selected for each pregnancy outcome depending on clinical plausibility, statistical significance, and size of outcome event rates (a full list of confounding factors controlled for in each analysis is available in the ESM 1: Confounding factors). Confounding factors controlled for in logistic regression analyses were chosen on the basis of theoretical clinical significance and initial Pearson's $\chi^{2}$ analyses, where the $P$ value was $<0.25$. Preliminary logistic regression analyses enabled the subsequent removal of potential confounding variables, with a $P$ value of $>0.5$, with the exception of instances in which the coefficient change of the exposure variable was $>20 \%$. The final logistic regression models for pregnancy outcome included statistically significant variables and clinically plausible interactions only. The threshold for retaining these variables in the final logistic regression model was $P<0.05$. Potential multicollinearity among the independent variables was identified using multiple regression analysis. Tolerance values for multicollinearity were set at $>0.5$. Hosmer and Lemeshow goodness-of-fit tests $>0.5$ indicated robust models and were considered valid in the logistic regression analyses. All statistical analyses were performed with the Statistical Package for Social Sciences SPSS for Windows version 16.1 (SPSS, Chicago, IL, USA). Risk ratio estimates are given as odds ratios (OR) with 95\% confidence intervals (CI).

\section{Results}

Of the 67,982 pregnant women in the study, 2,666 (3.9\%) used codeine during pregnancy (exposed group), whereas $65,316(96.1 \%)$ did not (unexposed group). In the exposed 
Table 1 Maternal characteristics of the study population

\begin{tabular}{|c|c|c|c|c|}
\hline & \multicolumn{2}{|c|}{$\begin{array}{l}\text { Women who used codeine during } \\
\text { pregnancy; exposed group }(n=2,666)\end{array}$} & \multicolumn{2}{|c|}{$\begin{array}{l}\text { Women who did not use opioids during } \\
\text { pregnancy: unexposed group }(n=65,316)\end{array}$} \\
\hline & No. & $\%$ & No. & $\%$ \\
\hline \multicolumn{5}{|l|}{ Maternal age (years) } \\
\hline$<20$ & 32 & 1.2 & 714 & 1.1 \\
\hline $20-29$ & 1,194 & 44.8 & 28,840 & 44.1 \\
\hline $30-39$ & 1,380 & 51.8 & 34,530 & 52.9 \\
\hline$\geq 40$ & 60 & 2.2 & 1,234 & 1.9 \\
\hline \multicolumn{5}{|l|}{ Parity } \\
\hline 0 & 1,153 & 43.2 & 28,523 & 43.7 \\
\hline$\geq 1$ & 1,513 & 56.7 & 36,787 & 56.3 \\
\hline \multicolumn{5}{|l|}{ Plurality } \\
\hline 1 & 2,611 & 97.9 & 64,123 & 98.2 \\
\hline$>1$ & 55 & 2.1 & 1,193 & 1.8 \\
\hline \multicolumn{5}{|l|}{ Ethnicity } \\
\hline Of Norwegian descent & 2,572 & 96.5 & 61,782 & 94.6 \\
\hline Not of Norwegian descent & 94 & $3.5^{*}$ & 3,534 & 5.4 \\
\hline \multicolumn{5}{|l|}{ Marital status } \\
\hline Married/cohabiting & 2,553 & 95.8 & 63,484 & 97.2 \\
\hline Other & 113 & $4.2^{*}$ & 1,832 & 2.8 \\
\hline \multicolumn{5}{|l|}{ Education } \\
\hline Primary & 80 & 3.0 & 1623 & 2.5 \\
\hline Secondary & 1,005 & 37.7 & 20,803 & 31.8 \\
\hline Tertiary & 1,525 & $57.2^{*}$ & 41,607 & 63.4 \\
\hline \multicolumn{5}{|l|}{ BMI prior to pregnancy $\left(\mathrm{kg} / \mathrm{m}^{2}\right)$} \\
\hline$<18.5$ & 65 & 2.4 & 2,002 & 3.1 \\
\hline $18.5-25.0$ & 1,479 & 55.5 & 41,930 & 64.2 \\
\hline$>25.0$ & 1,050 & $39.4^{*}$ & 19,483 & 29.8 \\
\hline Folic acid intake prior to pregnancy & 596 & 22.3 & 15,041 & 23.0 \\
\hline Sick leave lasting longer than 2 weeks during pregnancy & 1,023 & $38.4^{*}$ & 20,505 & 31.4 \\
\hline Smoking at gestational week 30 & 391 & $14.7^{*}$ & 6,180 & 9.4 \\
\hline Alcohol intake during pregnancy ${ }^{\mathrm{a}}$ & 1,421 & $53.3^{* *}$ & 3,3512 & 51.3 \\
\hline
\end{tabular}

Some data do not add up to the total due to missing values

* Pearson's $\chi^{2}$ test $P<0.001$ when compared with the unexposed control group,

** Pearson's $\chi^{2}$ test $P<0.05$ when compared with the unexposed control group

${ }^{a}$ Including data on sporadic intake and intake before the women were aware of their pregnancy

group, 45 women used codeine alone and 2,621 used codeine in a fixed combination with paracetamol. A higher proportion of exposed women had attained lower levels of education, were not married or cohabiting with their partner, were overweight (had a body mass index $>25 \mathrm{~kg} / \mathrm{m}^{2}$ ) prior to pregnancy, and smoked throughout pregnancy (Table 1). Moreover, these women were more likely to suffer from medical complications both prior to and during pregnancy (Table 2). Concomitant nonsteroidal antiinflammatory drug and psychotropic agent use was also significantly higher in the exposed group than in the unexposed group (Table 3). No significant difference was found in the survival rate of infants when comparing the exposed (99.4\% live births) with the unexposed (99.2\% live births) groups (adjusted OR 0.9, 95\% CI 0.6-1.5] (Table 4). No significant difference in overall congenital malformation rate was found when comparing the exposed $(4.9 \%)$ with the unexposed $(5.0 \%)$ group (adjusted OR 0.9, 95\% CI 0.8-1.1). No significant difference in the major congenital malformation rate was found between the exposed $(2.9 \%)$ and unexposed $(2.9 \%)$ group (adjusted OR 0.9, 95\% CI 0.7-1.2) (Table 4).

Codeine use anytime during pregnancy was significantly associated with an increased risk of acute Cesarean delivery (12.8\% in the exposed group compared with $8.9 \%$ in the 
Table 2 Maternal health and pregnancy complications

\begin{tabular}{|c|c|c|c|c|}
\hline & \multicolumn{2}{|c|}{$\begin{array}{l}\text { Women who used codeine during } \\
\text { pregnancy: exposed group }(n=2,666)\end{array}$} & \multicolumn{2}{|c|}{$\begin{array}{l}\text { Women who did not use opioids during } \\
\text { pregnancy: unexposed group }(n=65,316)\end{array}$} \\
\hline & No. & $\%$ & No. & $\%$ \\
\hline \multicolumn{5}{|l|}{ Maternal health during pregnancy } \\
\hline Acute musculoskeletal pain & 2,534 & $95.0^{*}$ & 58,005 & 88.8 \\
\hline Migraine and/or headache & 1,536 & $57.6^{*}$ & 23,115 & 35.4 \\
\hline Proteinuria & 766 & $28.7^{*}$ & 13,262 & 20.3 \\
\hline Temperature $>38.5^{\circ} \mathrm{C}$ fever associated with a rash & 590 & $22.1^{*}$ & 10,453 & 16.0 \\
\hline Hospitalization $^{* *}$ & 270 & $10.1^{*}$ & 2,839 & 4.3 \\
\hline Urinary tract infection and/or pyelonephritis & 258 & $9.7 \%{ }^{* * * a}$ & 5,371 & 8.2 \\
\hline Preeclampsia and/or eclampsia & 157 & $5.9^{*}$ & 2,592 & 4.0 \\
\hline Involved in an accident & 122 & $4.7^{*}$ & 2,003 & 3.1 \\
\hline High blood pressure during the first trimester ${ }^{\mathrm{a}}$ & 65 & $2.4^{*}$ & 998 & 1.5 \\
\hline \multicolumn{5}{|l|}{ Maternal health prior to pregnancy } \\
\hline Musculoskeletal pain (any) & 1,892 & $71.0^{*}$ & 34,562 & 52.9 \\
\hline $\begin{array}{l}\text { Arthritis/Systemic Lupus Erythematosus/ } \\
\text { Fibromyalgia }\end{array}$ & 348 & $13.0^{*}$ & 2,504 & 3.8 \\
\hline Depression & 258 & $9.7^{*}$ & 3,533 & 5.4 \\
\hline Asthma & 190 & $7.1^{*}$ & 2,885 & 4.4 \\
\hline Cardiac disease & 140 & $5.2^{*}$ & 2,108 & 3.2 \\
\hline Thyroid disorder & 70 & $2.6^{* * * * *}$ & 1,293 & 2.0 \\
\hline Diabetes (type I or II) & 44 & 1.6 & 810 & 1.2 \\
\hline \multicolumn{5}{|l|}{ Obstetric complications } \\
\hline \multicolumn{5}{|l|}{ Number of ultrasound examinations } \\
\hline$<2$ & 462 & 17.3 & 15,491 & 23.7 \\
\hline $2-4$ & 1,255 & 47.1 & 30,366 & 46.5 \\
\hline$>5$ & 650 & $24.3^{*}$ & 10,205 & 15.6 \\
\hline Vaginal bleeding during pregnancy ${ }^{\mathrm{b}}$ & 601 & $22.5^{*}$ & 11,979 & 18.3 \\
\hline First trimester & 498 & $18.7^{*}$ & 10,027 & 15.3 \\
\hline Second and/or third trimesters & 226 & $8.5^{*}$ & 4,295 & 6.6 \\
\hline Oligohydramnios & 62 & 2.3 & 1,506 & 2.3 \\
\hline Placenta previa & 46 & $1.7^{* * * *}$ & 821 & 1.3 \\
\hline Polyhydramnios & 32 & 1.2 & 556 & 0.8 \\
\hline Abruptio placentae & 17 & 0.6 & 271 & 0.4 \\
\hline
\end{tabular}

* Pearson's $\chi^{2}$ test $P<0.001$ when compared with the unexposed control group,

** Excluding hospitalization due to vaginal bleeding and high blood pressure,

**** Pearson's $\chi^{2}$ test $P<0.01$ when compared with the unexposed control group

***** Pearson's $\chi^{2}$ test $P<0.05$ when compared with the unexposed control group.

${ }^{a}$ Defined as systolic blood pressure $\geq 140 \mathrm{mmHg}$

${ }^{\mathrm{b}}$ Vaginal bleeding lasting more than 1 day or of an amount exceeding a trace or two or more episodes of bleeding or vaginal bleeding which has led to hospitalization

unexposed group) (adjusted OR 1.3, 95\% CI 1.1-1.5), planned Cesarean delivery $(7.4 \%$ in the exposed group compared with $5.0 \%$ in the unexposed group) (adjusted OR $1.4,95 \%$ CI $1.2-1.7)$, and postpartum hemorrhage (18.3\% in the exposed group compared with $14.5 \%$ in the unexposed group) (adjusted OR 1.2, 95\% CI 1.1-1.4) (Table 4).
Upon analyzing the effects of codeine on pregnancy outcome during the three specific trimesters, an increased risk of planned Cesarean delivery was seen after exposure in the first (7.3\%; adjusted OR 1.4, 95\% CI 1.1-1.7), second (7.5\%; adjusted OR 1.5, 95\% CI 1.2-1.8), and third (8.9\%; adjusted OR 1.6, 95\% CI 1.3-2.0) trimesters. Third 
Table 3 Frequency of concomitant nonsteroidal antiinflammatory drug and psychotropic agent use during pregnancy

\begin{tabular}{|c|c|c|c|c|}
\hline \multirow[t]{2}{*}{ Drug } & \multicolumn{2}{|c|}{$\begin{array}{l}\text { Women who used codeine during } \\
\text { pregnancy: exposed group }(n=2,666)\end{array}$} & \multicolumn{2}{|c|}{$\begin{array}{l}\text { Women who did not use opioids during } \\
\text { pregnancy: unexposed group }(n=65,316)\end{array}$} \\
\hline & No. & $\%$ & No. & $\%$ \\
\hline NSAIDs & 759 & $28.5^{*}$ & 8,271 & 12.6 \\
\hline Ibuprofen & 470 & $17.6^{*}$ & 6,269 & 9.6 \\
\hline Diclofenac & 170 & $6.4^{*}$ & 703 & 1.1 \\
\hline Naproxen & 85 & $3.2^{*}$ & 782 & 1.2 \\
\hline Other $^{\mathrm{a}}$ & 185 & $6.9^{*}$ & 1,323 & 2.0 \\
\hline Psychotropic agents & 359 & $13.5^{*}$ & 3,159 & 4.8 \\
\hline Antidepressants ${ }^{\mathrm{b}}$ & 172 & $6.4^{*}$ & 1,935 & 3.0 \\
\hline Anxiolytics ${ }^{\mathrm{c}}$ & 132 & $4.9^{*}$ & 788 & 1.2 \\
\hline Hypnotics $^{\mathrm{d}}$ & 86 & $3.2^{*}$ & 490 & 0.7 \\
\hline Antipsychotics ${ }^{\mathrm{e}}$ & 60 & $2.2^{*}$ & 452 & 0.7 \\
\hline
\end{tabular}

NSAIDS nonsteroidal anti-inflammatory drugs

*Pearson's $\chi^{2}$ test $P<0.001$ when compared with the unexposed control group

${ }^{a}$ Including piroxicam, meloxicam, indomethacin, acetylsalicylic acid, ketoprofen, nabumetone, and tolfenamic acid

${ }^{\mathrm{b}}$ Including selective serotonin reuptake inhibitors, tricyclic antidepressants, monoamine oxidase inhibitors, mianserin, mirtazapine, and venlafaxine

${ }^{\mathrm{c}}$ Including diazepam, oxazepam, alprazolam, hydroxyzine, and buspirone

${ }^{\mathrm{d}}$ Including nitrazepam, flunitrazepam, zopiclone, and zolpidem

${ }^{\mathrm{e}}$ Including levomepromazine, perphenazine, prochlorperazine, flupenthixol, zuclopenthixol, olanzapine, quetiapine, and risperidone

trimester use was, in addition, associated with an increased risk of acute Cesarean delivery (15.1\%; adjusted OR 1.5, $95 \%$ CI $1.3-1.8)$ and postpartum hemorrhage $(20.3 \%$; adjusted OR 1.3, 95\% CI 1.1-1.5) (Table 4). Subanalyses on the effect of codeine therapy duration on pregnancy outcomes revealed that codeine use lasting $>14$ days was significantly associated with planned (but not acute) Cesarean delivery (unadjusted OR 3.2, 95\% CI 1.3-7.9). No dose-effect relationship was found for postpartum hemorrhage.

\section{Discussion}

Information on the safety of analgesic use during pregnancy is an important issue for all clinicians prescribing these drugs to pregnant women. It is often not feasible to prescribe the more thoroughly documented nonopioid analgesics either for safety reasons or lack of adequate pain relief. The safety profiles of as many different analgesics as possible must be known before an individual risk-benefit evaluation can be done. In this study, codeine use during pregnancy was not found to be associated with infant survival rate, congenital malformation rate, or other adverse pregnancy outcomes, except for Cesarean delivery and excessive postpartum hemorrhage. Unlike previous studies $[4,5,7,8]$ and other medical literature sources that rely either on data regardng opioid analgesic use in general or a few case studies $[9,13]$, we found no increased risk of congenital malformations or neonatal respiratory depression. Associations of codeine use during pregnancy and neonatal abstinence syndrome were unfortunately not feasible to evaluate, as neonatal abstinence syndrome scores were not routinely applied. However, neither low Apgar scores nor admission of the neonate to intensive care were associated with codeine use during pregnancy, and these outcomes are also partly representative of neonatal abstinence syndrome.

Of other adverse pregnancy outcomes, the strongest association was between codeine use during pregnancy and increased risk of planned Cesarean delivery. This association remained significant, even after controlling for several clinically and statistically significant potential confounders, including high birth weight, fetal malpresentation, plurality, placenta previa, and others (a full list is available in the ESM 1: Confounding factors). A dose-effect relationship between codeine and planned Cesarean delivery was also detected. Nevertheless, we believe it is highly likely that the association was due to underlying medical conditions. Thirteen percent of exposed women suffered from chronic conditions, including arthritis, systemic lupus erythematosus, and fibromyalgia, compared with only $3 \%$ in the unexposed group; almost $10 \%$ had depression compared with only $5 \%$ of the unexposed women; a significantly 


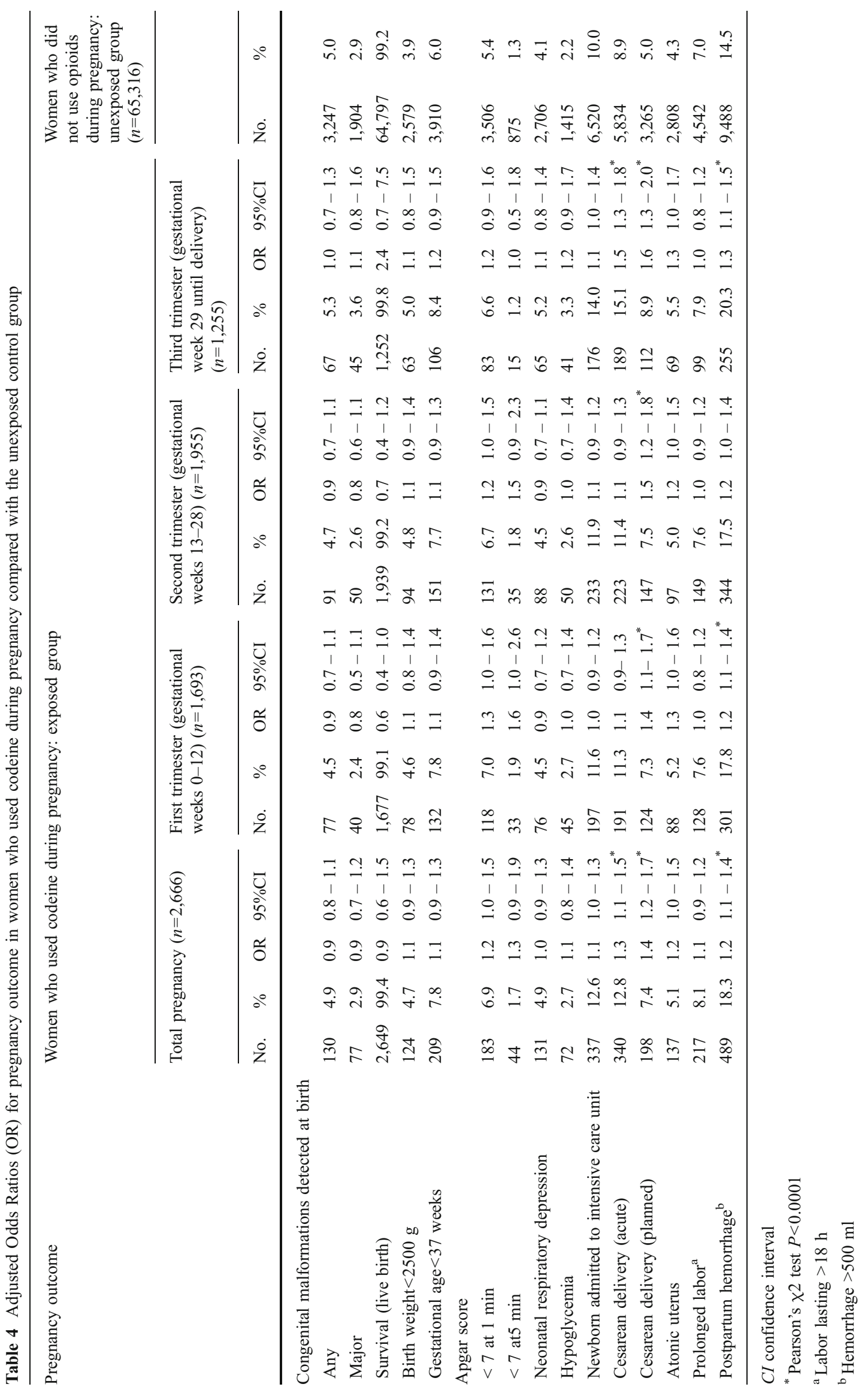


higher number of exposed women had asthma and cardiac disease; about $10 \%$ were hospitalized during pregnancy compared with $4 \%$ of the unexposed group; and $5.9 \%$ had preeclampsia and/or eclampsia compared with $4 \%$ of the unexposed group. Several of these diseases and conditions, which were not feasible to control for in this particular analysis, are associated with planned Cesarean delivery [18]. Association codeine therapy duration may also be indicative of the severity of the underlying medical conditions.

Notwithstanding, we cannot definitively exclude a direct association between codeine and acute Cesarean delivery and postpartum hemorrhage. A study on 315,085 pregnancies concluded that preeclampsia was significantly associated with postpartum hemorrhage and postulated that a deprivation of angiogenic factors resulting in the preeclamptic state may also play a role in postpartum hemorrhage [19]. It is also known that opioid analgesics administered during labor in the form of epidural analgesia are implicated in uterine atony [20,21]. Failure or weakening of myometrial contractions may result in excessive postpartum hemorrhage as well as Cesarean delivery [18]. However, atonic uterus and prolonged labor, cesarean delivery, induction of labor, epidural analgesia, third- or fourth-grade perineal tears and high birth weight, preeclampsia and/or eclampsia, placenta previa, and abruptio placentae, among others (a full list is available in the ESM 1: Confounding factors), were all controlled for in our analyses. It should be noted that the vast majority of women $(98.3 \%)$ in the exposed group used codeine in a fixed combination with paracetamol. However, we found no evidence of a possible association between paracetamol and increased risk of acute Cesarean delivery or postpartum hemorrhage.

Several study strengths and limitations merit specific attention. Our study is the only prospective cohort study on codeine use during pregnancy. Information derived from both MoBa and NMBR provided us with an extensive array of medical and sociodemographic characteristics of the study population. This enabled us to control for a very large number of-but not all-important confounding factors. Several validity studies concluded that the accuracy of registration of major congenital malformations is satisfactorily high $[22,23]$. The prospective collection of the majority of data greatly reduced the risk of recall bias. Differential reporting by the pregnant women was also avoided, as their pregnancy outcome was unknown to most of them at the time of data collection. In contrast to many other large studies, the chances of obtaining false positive associations due to multiple testing were reduced by including a minimum number of cases (more than four) in the final analysis. Moreover, all associations that were statistically significant had $P$ values $<0.0001$. On the other hand, a difference in the prevalence of drug use and pregnancy outcomes in the study population compared with the general population may have occurred, as participant response rate was only $43.5 \%$. However, it has been shown that only minor differences $(<2 \%$ in absolute differences in sociodemographic variables) between MoBa participants and the general population of pregnant women exist, and no differences in the estimates of association measures were found between participants and the general population [15, 24]. Despite this, the risk of false negative associations due to underrepresentation of certain sociodemographic groups, possible underreporting of codeine use during pregnancy, and the rarity of some pregnancy outcomes such as major malformations, should be taken into account. Analyses on specific malformations could not be undertaken due to low statistical power. It was also not feasible to determine the codeine dose pregnant women used and the exact point in time it was taken.

In conclusion, the fact that codeine use during pregnancy had no effect on infant survival or congenital malformation rate is particularly reassuring considering the size and singularity of this cohort study and the accuracy of pregnancy outcome reporting. We found an association between codeine use anytime during pregnancy and planned Cesarean delivery and between third-trimester codeine use and acute Cesarean delivery and excessive postpartum hemorrhage. Whereas the increased risk of Cesarean delivery, in particular, may be caused by underlying medical conditions, a direct association between codeine use toward the end of pregnancy and acute Cesarean delivery and postpartum hemorrhage cannot be definitively excluded.

Grants The Norwegian Mother and Child Cohort Study is supported by the Norwegian Ministry of Health and the Ministry of Education and Research, NIH/NIEHS (contract no NO-ES-75558), NIH/NINDS (grant No.1 UO1 NS 047537-01), and the Norwegian Research Council/FUGE (grant no.151918/S10). We are grateful to all participants and their families for taking part in this study.

Conflict of interest The authors declare that they have no conflict of interest.

Open Access This article is distributed under the terms of the Creative Commons Attribution Noncommercial License which permits any noncommercial use, distribution, and reproduction in any medium, provided the original author(s) and source are credited.

\section{References}

1. Andrade S, Gurwitz J, Davis R, Chan A, Finkelstein J, Fortman K et al (2004) Prescription drug use in pregnancy. AJOG 191:398-407 
2. Rubin J, Ferencz C, Loffredo C, The Baltimore-Washington Infant Study Group (1993) Use of prescription and non-prescription drugs in pregnancy. J Clin Epidemiol 46:581-589

3. Engeland A, Bramness J, Daltveit A, Rønning M, Skurtveit S, Furu K (2008) Prescription drug use among fathers and mothers before and during pregnancy. A population-based cohort study of 106000 pregnancies in Norway 2004-2006. Br J Clin Pharmacol 65:653-660

4. Cook M, Olshan A, Guess H, Savitz D, Poole C, Blatt J et al (2004) Maternal medication use and neuroblastoma in offspring. Am J Epidemiol 159:721-731

5. Saxen I (1975) Associations between oral clefts and drugs taken during pregnancy. Int J Epidemiol 4:37-44

6. Bracken M, Holford T (1981) Exposure to prescribed drugs in pregnancy and association with congenital malformation. Obstet Gynecol 58:336-344

7. Mangurten H, Benawra R (1980) Neonatal codeine withdrawal in infants of nonaddicted mothers. Pediatrics 65:159-160

8. Reynolds E, Riel-Romero R, Bada H (2007) Neonatal abstinence syndrome and cerebral infarction following maternal codeine use during pregnancy. Clin Pediatr 46:639-645

9. Schaefer C, Peters P, Miller RK (2007) Drugs during pregnancy and lactation. Elsevier, Amsterdam

10. Mayet S, Groshkova T, Morgan L, Maccormack T, Strang J (2008) Drugs and pregnancy - outcomes of women engaged with a specialist perinatal outreach addictions service. Drug Alcohol Rev 27:497-503

11. Almario CV, Seligman NS, Dysart KC, Berghella V, Baxter JK (2009) Risk factors for preterm birth among opiate-addicted gravid women in a methadone treatment program. Am J Obstet Gynecol 201:326.e1-6

12. Vucinovic M, Roje D, Vucinovic Z, Capkun V, Bucat M, Banovic I (2008) Maternal and neonatal effects of substance abuse during pregnancy: our ten-year experience. Yonsei Med J 49:705-713

13. Briggs G, Freeman R, Yaffe S (2005) Drugs in pregnancy and lactation. Lippincott Williams \& Wilkins, Philadelphia
14. Norwegian Institute of Public Health (2010) The Norwegian Mother and Child Cohort Study. Oslo, Norway

15. Nilsen R, Vollset S, Gjessing H, Skjærven R, Melve K, Schreuder $P$ et al (2009) Self-selection and bias in a large prospective pregnancy cohort in Norway. Paediatr Perinat Epidemiol 23:597608

16. Norwegian Institute of Public Health (2010) Medisinsk fødselsregister. Oslo, Norway

17. WHO Collaborating Centre for Drug Statistics Methodology. ATC/DDD Index 2008

18. Leveno KJ, Cunningham FG, Alexander JM, Bloom SL, Casey BM, Dashe JS et al (2007) Williams manual of obstetrics: Pregnancy complications. McGraw-Hill, New York

19. Eskild A, Vatten LJ (2009) Abnormal bleeding associated with preeclampsia: a population study of 315,085 pregnancies. Acta Obstet Gynecol Scand 88:154-158

20. Liu EHC, Sia ATH (2004) Rates of caesarean section and instrumental vaginal delivery in nulliparous women after low concentration epidural infusions or opioid analgesia:systematic review. BMJ 329:293-298

21. Kjærgaard H, Olsen J, Ottesen B, Nyberg P, Dykes A-K (2008) Obstetric risk indicators for labour dystocia in nulliparous women: a multi-centre cohort study. BMC Pregnancy Childbirth $8: 1-8$

22. Melve K, Lie R, Skjærven R, Van Der Hagen C, Gradek G, Jonsrud C et al (2008) Registration of Down syndrome in the Medical Birth Registry of Norway: validity and time trends. Acta Obstet Gynecol Scand 87:824-830

23. Kubon C, Sivertsen A, Vindenes H, Abyholm F, Wilcox A, Lie R (2007) Completeness of registration of oral clefts in a medical birth registry: a population-based study. Acta Obstet Gynecol Scand 86:1453-1457

24. Magnus P, Irgens L, Haug K, Nystad W, Skjærven R, Stoltenberg $\mathrm{C}$ et al (2006) Cohort profile: The Norwegian mother and child cohort study (MoBa). Int J Epidemiol 35:1146-1150 